\title{
Announcement: Award-winning paper in 2007
}

Papers published in Bridge Engineering are eligible for awards from the Institution of Civil Engineers. Papers from any ICE journal can be nominated for several awards. In addition, each journal has awards dedicated to its specific subject area.

On 24 October 2008, ICE President David Orr presented an award to the following paper published in Bridge Engineering in 2007. The Editorial Advisory Panel nominated their best papers and an awards committee chaired by Adrian Long allocated the award.

The John Henry Garrood King Medal, Presented for the best paper on bridges was awarded to Redpath J. Pendel bearing replacement at A9 Kessock Bridge, Scotland. Proceedings of the Institution of Civil Engineers, Bridge Engineering, 2007, 160, No. 4, 195-204. doi:10.1680/bren.2007.160.4.195

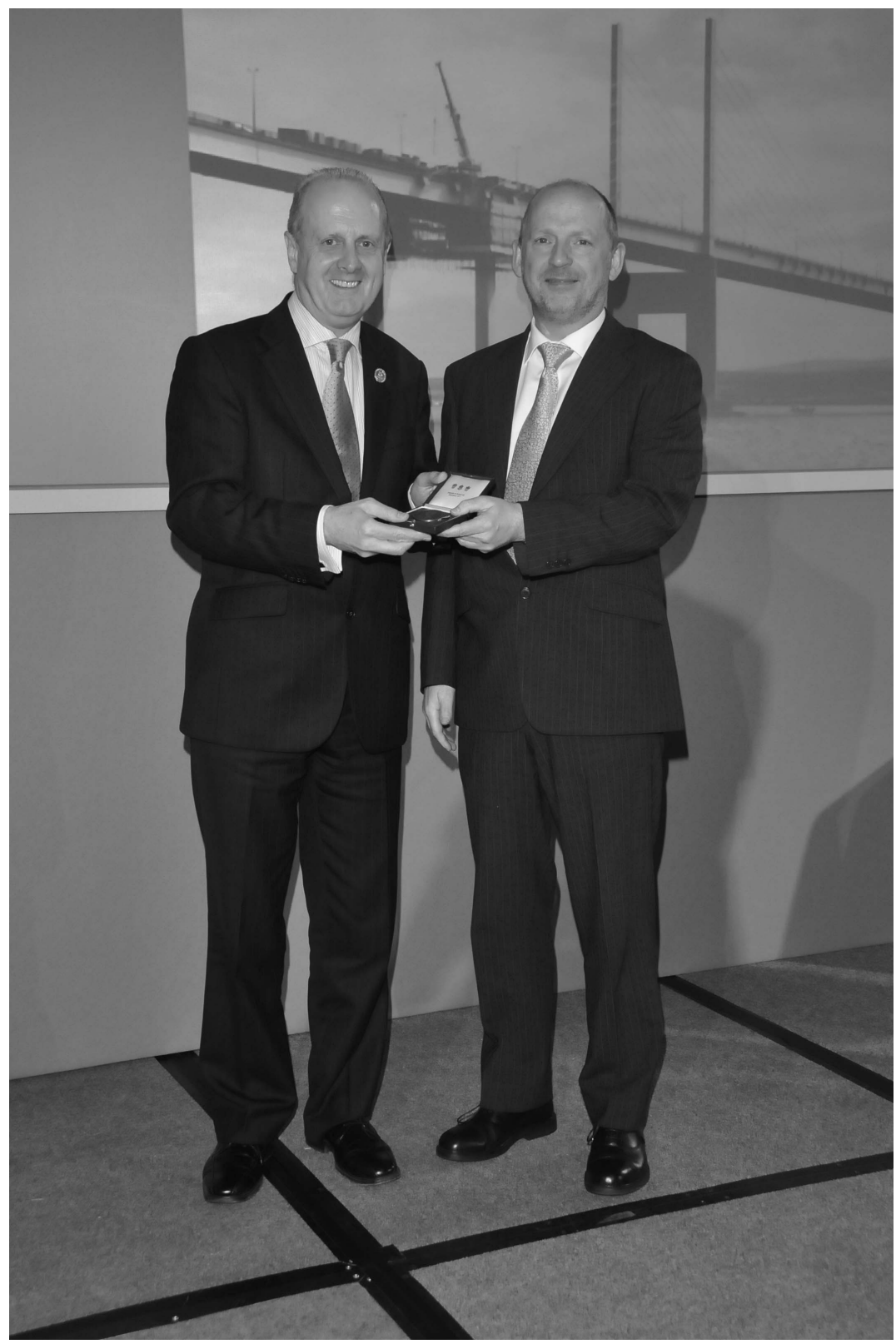

